\title{
A Review on Returnless Refunds in E-Commerce Retailing: Sales through Leniency
}

\author{
Guilherme Rodrigues dos Santos, Ekaterina Koromyslova \\ Department of Construction and Operations Management, South Dakota State University, Brookings, SD, USA \\ Email: ekaterina.koromyslova@sdstate.edu
}

How to cite this paper: dos Santos, G. R., \& Koromyslova, E. (2020). A Review on Returnless Refunds in E-Commerce Retailing: Sales through Leniency. iBusiness, 12, 69-80.

https://doi.org/10.4236/ib.2020.122005

Received: May 6, 2020

Accepted: June 26, 2020

Published: June 29, 2020

Copyright $\odot 2020$ by author(s) and Scientific Research Publishing Inc. This work is licensed under the Creative Commons Attribution International License (CC BY 4.0).

http://creativecommons.org/licenses/by/4.0/

(c) (i) Open Access

\begin{abstract}
Though the skyrocketing rate of product returns hurts profitability of retailers, those in e-commerce must continue to offer returns to remain competitive. Through the analysis of previous studies, we assert the positive effects of lenient return policies on a retailer's ability to gain and retain customers. This effect is explained by the relationship between return leniency, customer satisfaction and loyalty, and purchase intentions. Further, we investigate the individual product and customer factors that affect sales performance in relation to product returns. Building upon these premises, we offer that returnless refunds induce the desired customer response and suggest a layout for future studies.
\end{abstract}

\section{Keywords}

Returnless Refunds, Return Policies, E-Commerce Retailers, Purchase Intention, Consumer Behavior

\section{Introduction}

The environment of e-commerce revolves around retailers who regularly offer the same products at similar prices. When faced with such options, the consumer is compelled to make their purchase choice based on service levels. In this environment, competition rests primarily on the service each retailer offers. For consumers shopping online, the most impactful service offering is customer service, ease of purchase, and ease of return (Anderson et al., 2009) (Mukhopadhyay \& Setoputro, 2004).

Since allowing product returns increases a retailers' revenue and return rate (Janakiraman et al., 2016), we aim to understand how much each of these factors are impacted. A more lenient return policy leads customers to perceive a higher quality of retailer, which creates a sense of trust and boosts purchase intentions 
(Oghazi et al., 2018). A properly implemented return policy provides the e-commerce retailer with a favorable strategy that drives value and is quite beneficial (Janakiraman et al., 2016) (Hjort, 2013).

Customers assess return policies by their level of leniency; lenient policies have a large positive impact on the number of customers, product demand, and retailer profit (Batarfi et al., 2017). This study presents returnless refunds as a distinct return policy and seeks to understand how it will impact the e-commerce retailer and customer. Returnless refunds allow a customer to keep a product they wish to return while still receiving their refund. The implementation of returnless refunds offers e-commerce retailers an opportunity to reduce reverse logistics costs while presenting the customer with a hassle-free return and a potential gift, which should drive customer satisfaction, sales levels, and referrals (Oghazi et al., 2018). While Amazon has led the charge and offered returnless refunds since 2017, the practice continues to grow. In the past year Returnly, a company that manages returns for multiple e-commerce retailers, has begun supporting this type of return across its entire platform.

\section{Background}

The United States (U.S.) Census Bureau releases quarterly reports with the total sales and sales growth of retailers in the U.S. These reports show a consistent trend of expansion. In the report released in the $4^{\text {th }}$ quarter of 2018 , retail sales in the U.S. surpassed the $\$ 5.3$ trillion mark, while the national GDP was around $\$ 20$ trillion during the same period. E-commerce accounted for $9.65 \%$ of all retail sales in 2018. Ten years ago, this share of the market was less than $4 \%$ and is expected to continue increasing (U.S. Department of Commerce, 2019). During this period, while e-commerce retailers continued to invest heavily in creating a robust supply chain to support order fulfillment and returns management (Batarfi et al., 2017), they often haphazardly handled returns management by accepting it as a cost of doing business rather than attempting to optimize it (Rao et al., 2014). Today product returns have reached an unmanageable rate (Janakiraman et al., 2016), and retailers return policies are key competitive features they can no longer ignore (De Araújo et al., 2017). Failing to offer a generous return policy has a big impact on customer satisfaction (Dailey \& Ülkü, 2018).

Lenient return policies increase the probability of new customers returning to shop with the same e-commerce retailer. These policies boost the frequency of orders for new and existing customers, but they can also increase the return rate of purchases (Janakiraman et al., 2016) (Hjort, 2013). Therefore, there is a need to understand better the interaction between positive and negative factors related to e-commerce returns management. Although many studies have investigated conventional brick-and-mortar stores, research is scarce on the e-commerce arena (Fu et al., 2016) (Hjort \& Lantz, 2016). As returns management is an important topic, we will review current literature and follow with the introduction of new concepts (De Araújo et al., 2017) that empower further studies and will enable e-commerce retailers to make better strategic decisions (Hjort, 2013). 
This study will 1) highlight the potential for e-commerce retailers to use returnless refunds as a most lenient return policy and 2) propose a method to determine in which situations to use this policy. The purpose of this study is to suggest hypotheses for further research in the area of returnless refunds. The recommendations outline an approach to help e-commerce retailers increase sales performance through elevated customer satisfaction, which is enhanced by offering hassle-free returns. This study will be delimited to direct-to-customer e-commerce retailers, and it will not explore any brick-and-mortar merchants. This limitation means returnless refunds will not be compared to in-store returns of online purchases, which is another manner by which retailers can reduce their costs and the hassle to the customer returning an item. It also will not observe the difference in industry specific features, impact of seasonal variability, or issues related to return fraud.

Our study will comprise of a literature review, discussion of the current body of knowledge and background information on the study topic. The literature review includes an analysis of return policies, components of customer satisfaction, and drivers of e-commerce sales. The literature review will also discuss hypotheses for further research and examine the implications of such suggestions.

\section{Literature Review}

Today, more than ever, consumers are expected to trust the fit, quality, and utility of merchandise solely through pictures, description, and reviews (Fu et al., 2016). Online retailers can attempt to reduce potential purchase apprehension by increasing trustworthiness via lenient return policies (Huseynov \& Yildirim, 2014). At the same time, retailers need to ensure they minimize the cost of these returns to achieve profitability (Anderson et al., 2009).

First, to highlight the importance of returns management, we review the condition of the retail market and environment of e-commerce specifics. We then present takeaways from previous literature on return policies and their interaction with consumer behavior. Finally, we identify the shortcomings of current models by explaining the action-reaction phenomena of returnless refunds in shaping consumer behavior to drive profitability.

\subsection{Retail and E-Commerce}

Much of e-commerce's growth can be attributed to convenience and the myriad of options e-commerce provides consumers in the comfort of their homes (Fu et al., 2016). Not only do consumers benefit from nearly infinite options, but online retailers also see in this new trend a chance to reach more customers. Advancements in e-commerce have directly translated into the popularization of the Business-to-Consumer (B2C) model, providing retailers of all sizes a platform to interact directly with consumers (Huseynov \& Yildirim, 2014). Consumers armed with their newfound ability to compare multiple options have sent the market into a competitiveness frenzy (Huseynov \& Yildirim, 2014). Therefore, 
online retailers must attempt to remove inefficiencies and reduce prices while maintaining a high level of quality to keep customers happy since e-commerce is susceptible to the quick spread of negative feedback (Bonifield et al., 2010).

Throughout the past two decades, online retailers have faced an ever-increasing level of product returns, and, if no action is taken, this trend is expected to stay the course (Dailey \& Ülkü, 2018) (Bower \& Maxham, 2012). Product returns are an expensive problem and, while online retailers attempt to lower return rates, they remain aware of the returns importance in their business. The ability to return an item is invaluable when the consumer cannot physically see it prior to completing the purchase (Rao et al., 2014). Some e-commerce retailers have experimented with more stringent return policies that have caused an undesired effect from consumers who decide to shop elsewhere; some retailers who have experimented with more lenient policies have suffered with the incurred costs (Janakiraman et al., 2016). Either way, the conclusion is that e-commerce retailers must offer product returns.

\subsection{Consumer Behavior}

Online retailers face the need to establish a relationship of trust with consumers to drive up purchase rates. This is especially important for retailers who strictly engage in e-commerce. Retailers attempt to build this trust by publishing reviews from previous customers and by providing guarantees of satisfaction, particularly a favorable return policy (Oghazi et al., 2018). As presented in Figure 1 consumer trust drives up the purchase intentions and inherently the volume of sales. Then through its product quality and customer service, the retailer builds the satisfaction and loyalty needed to ensure repeat customers. Hjort and Lantz (Hjort \& Lantz, 2016) and Mukhopadhyay and Setoputro (Mukhopadhyay \& Setoputro, 2004) have demonstrated that the ability to drive consumer behavior with return policies make it a competitive tool. Online retailers would fail if they choose to not offer returns.

E-commerce retailers require a broader strategy than haphazardly offering product returns. The success of an online retailer comes from the ability to attract new customers and retain old ones, which requires a retailer to excel in customer service to build consumer loyalty and ensure repeat purchases (Ramanathan, 2011). However, in building consumer loyalty, online retailers must understand the behavior and priorities of their customers (Hjort, 2013). While free-return policies can stimulate increased sales, the policies also increase returns, which results in higher costs for the company. Anderson, Hansen, and Simester (Anderson et al., 2009) have shown that customers quickly become angry at the absence of product returns; however, Ramanathan (Ramanathan, 2011) has also shown that a customer-assigned value to returns is dependent on the price of the product. Bonifield, Cole, and Schultz (Bonifield et al., 2010) took it further in demonstrating that while customers who purchase non-consumables equate the return policy to retailer quality, this paradigm does not hold true for consumable products. 


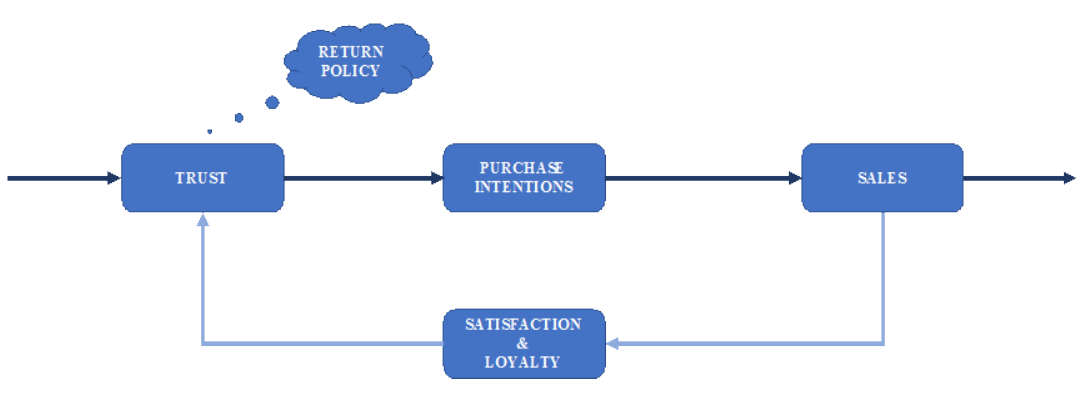

Figure 1. Sales driven by consumer behavior in response to return policy.

\subsection{Return Policies}

Offering returns is quite costly, therefore, to minimize inefficiencies, an online retailer often uses a comprehensive return policy. This policy aligns the offering of product returns with the retailer's overall strategy in winning and keeping customers (Batarfi et al., 2017). Return policies have varying degrees of leniency that depend highly on the strategy used by the online retailer (Huseynov \& Yildirim, 2014). Janakiraman, Syrdal, and Freling (Janakiraman et al., 2016) dissect the leniency of return policies into five separate factors: money, effort, time, exchange, and scope.

Money leniency defines if shipping, handling, and restocking fees are charged from customers returning products. Effort leniency defines the stipulations around how the product is returned such as requiring original packaging or receipt. Time leniency defines the length of time allowed for a customer to return a product. Exchange leniency defines whether a retailer offers cash returns or only store credit, and scope leniency defines which products may or may not be returned (Janakiraman et al., 2016). Online retailers need to achieve a balance in providing a return policy that is attractive to consumers while protecting themselves from creeping costs (Return to vendor, 2012), and an online retailer needs to know what drives causes for returns. This allows for assessing and adjusting the offered return policy properly (Hjort, 2013) (Fu et al., 2016).

Oghazi, Karlsson, Hellström, and Hjort (Oghazi et al., 2018) show that a more lenient return policy displays to consumers the retailer's willingness to share the risks of the transaction. This creates trust and goodwill, which drives loyalty and may result in referrals. Given the benefits of offering a lenient return policy and the difficulty of setting a strategy for return management, retailers are encouraged to err on the side of leniency, which benefits the retailer (Janakiraman et al., 2016). Although e-commerce has access to a plethora of available data, the online retailers often fail to analyze the root causes of returns in order to forecast and curb returns negative effects (Rao et al., 2014). Returned products can carry many hidden costs. It begins with shipping back to the online retailer. It then requires handling and, finally, resale at a decreased price. Some products end up damaged, expired, or obsolete and must be discarded (Fu et al., 2016). Even with these negatives and the growing rates of returns, Dailey and Ülkü (Dailey \& Ülkü, 2018) have shown that a lenient return policy is still the best approach for e-commerce retailers. 


\subsection{Leniency Models}

Previous researchers have proposed different models while studying the decision-making process of retailers in establishing return policies for e-commerce. These models follow similar approaches that analyze features from the return policy, consumer, and product. We combine these models to create an understanding of the impact of the return policy on the profitability of e-commerce retailers. This understanding can then be used to evaluate the efficiency of offering returnless refunds.

Janakiraman, Syrdal, and Freling (Janakiraman et al., 2016) propose a method in which the return policy factors (money, effort, time, exchange, and scope) are considered against product factors to infer intention of purchase and intention of return by customers. Bonifield, Cole, and Schultz (Bonifield et al., 2010) offer that the consumability of a product should become a key factor on the customer's reaction to return policies with leniency on non-consumables signaling to customers a retailer's high quality. Anderson, Hansen, and Simester (Anderson et al., 2009) prove that price of product is another key factor. The lower the price of the product the less value a customer places on being able to return it. In contrast, Ramanathan (Ramanathan, 2011) offers that the price of a product is inversely related to a customer's appreciation for how their returns are handled. Additionally, Anderson et al. (Anderson et al., 2009) proposed the appraisal of uncertainty of product fit, and Rao, Rabinovich, and Raju (Rao et al., 2014) proposed taking into account the scarcity of product being offered, but both ideas are not implementable in a general context.

While product factors, such as consumability and price, are quite straightforward, the five factors of leniency require further understanding. Data presented by Janakiraman, Syrdal, and Freling (Janakiraman et al., 2016) establish the following: 1) added leniency on money and effort factors increase purchase intention of a customer, while 2) added leniency on time and exchange decreases return intention, and 3) added leniency on scope increases the return intention. The opportunity then exists for creating a mixed model where a balance can be found between purchase intention and return intention that translates into the volume to margins trade-off (Anderson et al., 2009).

Both $\mathrm{Fu}$ et al. (Fu et al., 2016) and Gronholdt, Martensen, and Kristensen (Gronholdt et al., 2000) assert that the expectations of a customer concerning return policies and product features directly impact the effectiveness of return policies in driving customer behavior. By establishing realistic expectations, an e-commerce retailer builds trust. The more trust a customer places in a retailer, the higher a customer's purchasing rate (Huseynov \& Yildirim, 2014). In this same line, increased leniency in a return policy alleviates a customer's apprehension and raises trust (Janakiraman et al., 2016), leading to higher purchase rates. As expected, opposite actions result in opposite results. Less leniency upsets customers (Anderson et al., 2009) and a lack of trust negatively affects the rate of purchases (Huseynov \& Yildirim, 2014). Finally, Oghazi, Karlsson, Hellström, and Hjort (Oghazi et al., 2018) link return policy and sales; they demonstrate 
that lenient return policies generate consumer trust and that consumer trust increases purchase intentions, which in turn drives sales.

\subsection{Modifying Factors}

With the reach of the internet, e-commerce retailers now cater to an unheard variety of customers. This diversity creates its own set of issues. No longer can a single solution fit every situation (Hjort, 2013); therefore, an ideal strategy for returns management requires segmented return policies that cater to specific groups or individual customers (Hjort \& Lantz, 2016). Since the perceived value of returns changes with the demographic characteristics of different customers, we can safely conclude that distinct characteristics will produce distinct results (Dailey \& Ülkü, 2018). The demographic characteristics that describe each customer must be used as moderating factors to properly model the effect of return leniency on sales performance. The analysis of these models can be quite complex, and the addition of such moderating factors ensures more accurate results (Hjort \& Lantz, 2016).

A successful strategy for returns management requires e-commerce retailers to understand the critical factors impacting, negatively or positively, their customers' purchase and return dispositions. Different demographic groups react differently to a given condition (Fu et al., 2016), thus the critical factors are highly susceptible to the influence of these demographics, but if handled correctly these factors provide the retailer an incredible competitive advantage (Huseynov \& Yildirim, 2014). Furthermore, because critical factors directly impact sales performance, these performances then become bound to the demographic characteristics of a retailer's customers (Fu et al., 2016). Vast studies conducted around this premise have collected the necessary data by creating experiments and surveying both undergraduate and graduate students, demonstrating this to be an appropriate approach (Oghazi et al., 2018) (Dailey \& Ülkü, 2018) (Huseynov \& Yildirim, 2014) (Bonifield et al., 2010) (Stouthuysen et al., 2018).

Anderson, Hansen, and Simester (Anderson et al., 2009) propose classifying customers by their income, age, and size of household, which they justify through supporting data. The data asserts that the three factors correlate, respectively, in descending order of impact, to a customer's perceived value of return. Dailey and Ülkü (Dailey \& Ülkü, 2018) offer slightly different factors and propose the use of income, age, and gender. Since a sensitivity analysis is not performed, these factors may not be ordered on their importance to the model. Oghazi, Karlsson, Hellström, and Hjort (Oghazi et al., 2018) introduce an additional perspective and a more advanced list of moderating factors. Frequency of online shopping, level of computer skills, annual income, education, and gender. These factors are also organized in descending order of impact, as told by the correlation matrix provided by the authors. Additionally, Fu et al. (Fu et al., 2016) recommend the use of gender, location, and credit score. Due to the non-locality of e-commerce shopping, and difficulty in accessing credit scores, this recommendation has not been taken into consideration. 
Deriving from the factors reviewed above, we seek to investigate gender and age further, due to their prevalence as available data. Huseynov and Yildirim (Huseynov \& Yildirim, 2014) suspect gender of influencing the purchase intentions of e-commerce customers. Fu et al. (Fu et al., 2016) prove this theory by demonstrating that females return more than males. Anderson, Hansen, and Simester (Anderson et al., 2009) then add that, due to lower return rates and fewer dedicated e-commerce retailers, males are often afforded longer periods to return products. Age is not as straightforward, instead it is used to separate customers into generational groups, which are then considered. As a result of early exposure to electronics, younger generations show much higher rates of internet usage and computer proficiency (Oghazi et al., 2018). More so than older generations, these generations therefore display a comfort with navigating e-commerce stores, shopping more and more often from e-commerce retailers (Oghazi et al., 2018). In another display of generational differences, younger customers show concern for the privacy of their personal data, while older customers prioritize instead the security of their financial data (Huseynov \& Yildirim, 2014).

In reviewing the different moderating factors, we arrive at a combined model that accounts for utility of data and ease of access. This model joins the well-investigated age and gender factors and factors of income and frequency of online shopping. Income has continuously proven to be a good indicator of a customer's attraction to products and care for return policies (Anderson et al., 2009). While frequency of online shopping draws its usefulness from the indisputable matter, frequent e-commerce shoppers continue shopping more and more often than other users (Stouthuysen et al., 2018).

These four customer-moderating factors-age, gender, income and frequency of online shopping-should provide researchers and e-commerce retailers the ability to group customers by demographics with enough distinction and little introduction of error. Then, the combination of this data with the moderating product factors, consumability and price, builds the array of variables shown in Table 1 that influence the outcomes of different return policies. This combination of customer and product data greatly enhances the assessment of return policies and their impact on sales performance (Fu et al., 2016). Such modifying factors need to be controlled when testing a return policy across different customer and product classifications in order to perform accurate comparisons. Ideally, this information would already be collected if surveys are performed, and it should be available if data is gathered at the retailer level.

Table 1. Moderating variables which impact consumer response to return policy.

\begin{tabular}{cc}
\hline PRODUCT FACTORS & CUSTOMER FACTORS \\
\hline & Income \\
Consumables vs. Non-Consumables & Age \\
High Price vs. Low Price & Gender \\
& Frequency of Online Shopping \\
\hline
\end{tabular}


The model proposed and shown in Figure 2 should be used on further research and trial programs. Different levels of return policy leniency must be tested on different combinations of moderating factors, as to determine the magnitude of impact in each scenario. These findings will then allow retailers to utilize a more dynamic return policy approach, adjusting it based on product and target demographic. Once a retailer understands the influence returnless refunds have in a specific product-customer combination, and the derived cost associated with offering such service, they can begin to expand the use of this most-lenient return policy. We propose that e-commerce retailers will see gains in both product sales and customer loyalty. We further present scenarios below in which envision positive results will be encountered.

\subsection{Proposed Hypotheses}

Hypothesis 1: Offering returnless refunds when handling returns of intimate articles of clothing shall result in a positive shift to net sales when all other factors are controlled. We expect that the return of undergarments is driven mostly by a misalignment in the expectation of fit. A customer who feels their return is handled properly is likely to perform a second purchase of the product in the correct size. Since most retailers do not resell returned undergarments due to health considerations, a returnless refund not only influences another purchase but also allows the retailer to avoid the additional cost of the reverse logistics. Through its demonstrated commitment to the customer in their purchase of correctly-fitting garments, the retailer builds the trust that drives sales.

Hypothesis 2: Offering returnless refunds when handling returns of lowpriced non-consumable home items shall result in a positive shift to net sales when all other factors are controlled. We expect since the return of home items is driven mostly by a misalignment in the expectations of quality or utility, a customer who is granted a returnless refund is afforded the opportunity to either gift or retain the product. A product that is gifted increases its visibility, which may create new customers, and a product that is kept and used may convince the customer positively of its quality over time. Given the greatly diminished margins, and possible losses, on reselling low-priced products after deducting the cost of reverse logistics, a retailer benefits instead from this use of returns management in creating new and returning customers to drive sales.

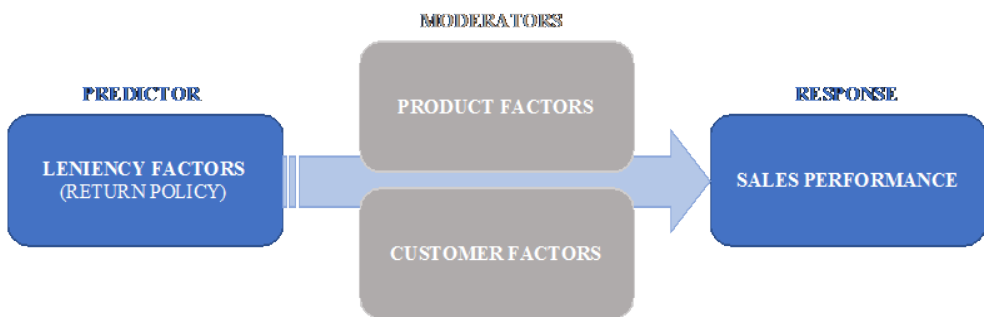

Figure 2. Suggested model for understanding impact of return leniency under different variables. 
Hypothesis 3: Offering returnless refunds when handling returns of new-tomarket products shall induce greater growth of net sales when all other factors are controlled. Due to the uncertainty surrounding new products, it can be challenging for customers to have accurate expectations in regard to fit, quality, and utility. In the case of a misalignment of these expectations, the retailer can then use returnless refunds to guarantee a satisfying engagement. This policy allows customers to purchase a new product with the peace of mind knowing the retailer vouches for it. As described in previous hypotheses, the customer's choice in gifting or retaining and using the product likely generates new or returning customers. This scenario also involves reducing reverse logistics costs and driving sales through established trust.

Hypothesis 4: Offering returnless refunds when handling returns from non-frequent shoppers of older age groups shall lead to a positive effect on net sales when all other factors are controlled. Since this group of customers often shops less online due to their unfamiliarity and apprehension, a poorly handled return can surely drive them away for good. Returnless refunds allow a retailer to forgive potential shopping errors, in either product selection or system use. It serves as a gesture of goodwill that builds a relationship of loyalty to create a long-lasting customer. Once these customers feel more comfortable with the retailer and online shopping as a whole, increased sales shall be observed.

\section{Conclusion and Summary}

E-commerce retailers offer product returns with the company's performance in mind and not necessarily the customer satisfaction, although these are often aligned (Gronholdt et al., 2000). Studies have established that return policies are a competitive tool needed to win and retain customers, and these policies have become more decisive in e-commerce than brick-and-mortar retailing (Mukhopadhyay \& Setoputro, 2004). Since e-commerce retailers aim to drive sales by increasing the purchase intention through the trust built with return policies, then these return policies are a strategy that creates value (Hjort, 2013). We propose that by implementing returnless refunds, a retailer may identify a positive impact on net sales-where the increase in sales outpaces the increase in returns-when compared to other policies. Further, we recommend the use of product factors (consumability and price) and customer factors (age, gender, income, and frequency of online shopping) in a moderating role, as those factors provide control of variability and allow for proper analysis of the return policy on sales performance. Further research will help understand the cost of offering returnless refunds, the cost and efficiency of other sales creation methods, and the integrated cost benefit of returnless refunds in e-commerce retailing.

The main contributions of the paper include discussion of the recent growth of e-commerce, review of previous research on return policies, and suggestions on future courses of action for researchers and practitioners. With this intent, we have discussed the concept of returnless refunds, a most-lenient return policy 
which is still in its infancy but is gaining popularity amongst e-commerce retailers. Since e-commerce continues to grow, the dollar amount associated with returns management has become key in the potential success or failure of all retailers, and, although counter-intuitive, lenient return policies have been shown to increase profits. Thus, we formulated hypotheses which future researchers can test to validate our propositions. E-commerce retailers may implement a returnless refund program with positive returns. The discussed framework and the highlighted factors can be used for analysis of the existing customer database, including a customer profile, order history, and purchase habits, to implement the differentiated approach for offering the returnless refunds and assessing its impact on future sales. Additionally, a comparison of the costs related to returnless refunds against the shipping cost and other costs associated with receiving returns, inspection, repackaging, and restocking, would be another determinant along with the discussed approach. However, our review was limited to e-commerce retailers only and did not account for features outside of the discussed product and customer factors. We also did not address the issue of return fraud and its implications in the review that could be a direction for future research.

\section{Conflicts of Interest}

The authors declare no conflicts of interest regarding the publication of this paper.

\section{References}

Anderson, E. T., Hansen, K., \& Simester, D. (2009). The Option Value of Returns: Theory and Empirical Evidence. Marketing Science, 28, 405-423. https://doi.org/10.1287/mksc.1080.0430

Batarfi, R., Jaber, M. Y., \& Aljazzar, S. M. (2017). A Profit Maximization for a Reverse Logistics Dual-Channel Supply Chain with a Return Policy. Computers \& Industrial Engineering, 106, 58-82. https://doi.org/10.1016/j.cie.2017.01.024

Bonifield, C., Cole, C., \& Schultz, R. L. (2010). Product Returns on the Internet: A Case of Mixed Signals? Journal of Business Research, 63, 1058-1065.

https://doi.org/10.1016/j.jbusres.2008.12.009

Bower, A. B., \& Maxham, J. G. (2012). Return Shipping Policies of Online Retailers: Normative Assumptions and the Long-Term Consequences of Fee and Free Returns. Journal of Marketing, 76, 110-124. https://doi.org/10.1509/jm.10.0419

Dailey, L. C., \& Ülkü, M. A. (2018). Retailers Beware: On Denied Product Returns and Consumer Behavior. Journal of Business Research, 86, 202-209. https://doi.org/10.1016/j.jbusres.2018.01.064

De Araújo, A. C., Matsuoka, E. M., Ung, J. E., Massote, A., \& Sampaio, M. (2017). An Exploratory Study on the Returns Management Process in an Online Retailer. International Journal of Logistics Research and Applications, 21, 345-362. https://doi.org/10.1080/13675567.2017.1370080

Fu, Y., Liu, G., Papadimitriou, S., Xiong, H., Li, X., \& Chen, G. (2016). Fused Latent Models for Assessing Product Return Propensity in Online Commerce. Decision Support Systems, 91, 77-88. https://doi.org/10.1016/j.dss.2016.08.002 
Gronholdt, L., Martensen, A., \& Kristensen, K. (2000). The Relationship between Customer Satisfaction and Loyalty: Cross-Industry Differences. Total Quality Management, 11, 509-514. https://doi.org/10.1080/09544120050007823

Hjort, K. (2013). On Aligning Returns Management with the e-Commerce Strategy to Increase Effectiveness (Unpublished Doctoral Dissertation). Goteborg: Chalmers University of Technology.

Hjort, K., \& Lantz, B. (2016). The Impact of Returns Policies on Profitability: A Fashion e-Commerce Case. Journal of Business Research, 69, 4980-4985. https://doi.org/10.1016/j.jbusres.2016.04.064

Huseynov, F., \& Yildirim, S. Ö. (2014). Internet Users' Attitudes toward Business-toConsumer Online Shopping. Information Development, 32, 452-465. https://doi.org/10.1177/0266666914554812

Janakiraman, N., Syrdal, H. A., \& Freling, R. (2016). The Effect of Return Policy Leniency on Consumer Purchase and Return Decisions: A Meta-Analytic Review. Journal of Retailing, 92, 226-235. https://doi.org/10.1016/j.jretai.2015.11.002

Mukhopadhyay, S. K., \& Setoputro, R. (2004). Optimal Return Policy and Modular Design for Build-to-Order Products. Journal of Operations Management, 23, 496-506. https://doi.org/10.1016/j.jom.2004.10.012

Oghazi, P., Karlsson, S., Hellström, D., \& Hjort, K. (2018). Online Purchase Return Policy Leniency and Purchase Decision: Mediating Role of Consumer Trust. Journal of Retailing and Consumer Services, 41, 190-200.

https://doi.org/10.1016/j.jretconser.2017.12.007

Ramanathan, R. (2011). An Empirical Analysis on the Influence of Risk on Relationships between Handling of Product Returns and Customer Loyalty in e-Commerce. International Journal of Production Economics, 130, 255-261. https://doi.org/10.1016/j.ijpe.2011.01.005

Rao, S., Rabinovich, E., \& Raju, D. (2014). The Role of Physical Distribution Services as Determinants of Product Returns in Internet Retailing. Journal of Operations Management, 32, 295-312. https://doi.org/10.1016/j.jom.2014.06.005

Return to Vendor (2012). A Dress on Loan; Retail Fraud. The Economist, 402, 79.

Stouthuysen, K., Teunis, I., Reusen, E., \& Slabbinck, H. (2018). Initial Trust and Intentions to Buy: The Effect of Vendor-Specific Guarantees, Customer Reviews and the Role of Online Shopping Experience. Electronic Commerce Research and Applications, 27, 23-38. https://doi.org/10.1016/j.elerap.2017.11.002

U.S. Department of Commerce (2019). Quarterly Retail e-Commerce Sales 4th Quarter 2018 (CB19-25). https://www2.census.gov/retail/releases/historical/ecomm/18q4.pdf 